\title{
Distensibility of the Fetal Lung with Fluid in Sheep
}

\author{
Jonathan T. Lanman ${ }^{221}$, Albert Schaffer, Llewellyn Herod, Yunosuke Ogawa, \\ and Roger Castellanos \\ Departments of Pediatrics and Comparative Biology, State University of New York, Downstate Medical Center, Brooklyn, New York, USA
}

\section{Extract}

Tracheal ligation was performed in 16 fetal lambs at 74-129 days of gestation (normal term, 138-157 days). Operated lambs were subsequently delivered spontaneously at term. Postmortem procedures were performed on the same day and revealed lungs enormously distended with fluid, weighing approximately 10 times more than those found in normal lambs, and displacing the diaphragm to the point where it was concave downward, bulging into the abdominal cavity. To measure the rate of lung fluid formation in fetal lambs, catheters were placed in the trachea of three fetuses borne by three ewes near term. Periodic aspiration of fluid following the operation revealed rates of lung fluid formation of $0.015,0.030$, and $0.055 \mathrm{ml} / \mathrm{kg} / \mathrm{min}$. The day after surgery pressure measurements of lung fluid made via the catheter in two of these animals revealed an initial pressure of 12 and $19 \mathrm{~cm}$ saline. This pressure rose only moderately after injecting $150 \mathrm{ml} 0.85 \% \mathrm{NaCl}$ in $20-\mathrm{ml}$ increments into the fetal lung. The injected fluid was readily recoverable, indicating that it had been accommodated by expansion of the fetal lung and had not passed across lung-lining cells into the fetal circulation. Gestation times were within the normal range.

\section{Speculation}

Fetal lung fluid contains surfactant, which has been biochemically characterized as a phospholipid and as a lecithin. Soya bean phospholipids containing a predominance of lecithins are capable of sensitizing the rabbit uterus to oxytocin and precipitating premature delivery. The fetus is known to participate in the timing of its own birth, and we speculated whether lung phospholipids formed near term in the fetal lung could reach the amniotic fluid and precipitate labor. Tracheal occlusion, however, did not alter gestation time in our animals. Other mechanisms of fetal participation in the precipitation of labor must be sought.

\section{Introduction}

Recent work $[5,9,14,18]$ has indicated that fetal lungs secrete fluicl. The fluid was thought to flow via the trachea to the oral pharynx, where it was either swallowed or passed via the nose or mouth into the amniotic fluid. Reynolds [17], however, published observations suggesting that with relatively minor pressure changes fluid would move in the reverse direction. He concluded that "it is clear that ... the fetal lung is a two-way diffusing system" and "when uterine contractions develop pressurcs of $20-60 \mathrm{~mm}$ of mercury, there can be a movement of fluicl in the reverse direction into the foctus." The implication appeared to be that fluid passed across the pulmonary epithelium, thereby entering the fetus.

We have recently made observations suggesting a somewhat different interpretation. First, we have found a 10 -fold increase in fetal lung weight at birth 
after fetal tracheal ligation near midterm; the lungs become distended with fluid as a sequel to the tracheal ligation. Second, in acute experiments near term we have confirmed that, with small increases in pressure, fluid can readily be made to flow into the fetal lung, but an approximately equal volume of fluid is recoverable when the pressure gradient is reversed. We belicve that the fetal lung is distensible at low pressures by fluid which can be accommodated by expansion of the lung.

\section{Materials and Methods}

Tracheal ligation was performed in fetal lambs at 74-129 days gestation (normal term, 138-157 days) [19]. Some of these fetuses were from Dorset Horn ewes, mated in our own laboratory. Others were from cross-bred ewes with dated pregnancies, purchased from the School of Agriculture, University of Connecticut. In both instances, ewes were mated under observation and testmated 16-18 days later; refusal to mate at this anticipated time of estrus was taken to indicate pregnancy.

The pregnant ewes were initially tranquilized with an intramuscular injection of propiopromazine and were then operated under either $1 \%$ pontocaine epidural block or paralumbar anesthesia. The fetal head and neck were exposed by hysterotomy. Double tracheal ligation was made with no. 12 cotton suture to minimize cutting of the trachea between the cartilaginous rings. Following ligation, the uterus and ablomen of the ewe were closed and the animal patient was kept under observation until lambing, which usually occurred at night. Following spontaneous delivery, the newborns, which died immediately after birth because of the tracheal occlusion, were examined promptly, and the integrity of the tracheal ligatures was tested by infusion of a solution of methylene blue dye below the ligature.

To measure the rate of lung fluid formation in the fetus, catheters were placed in the tracheas of the fetuses carried by three pregnant ewes near term, one at 145 days, one at 143 days and one with an undated pregnancy, but near term as evidenced by the letting down of milk by the ewe, which usually occurs about 5 days before lambing. In each case, the fetus was left in utero, and the uterus and abdomen were closed. The catheter was placed under the skin and brought out over the lumbar area of the ewe. After recovery from anesthesia, with the ewc standing, no fluid flowed spontaneously from this catheter, but fluid was aspirated periodically at timed intervals over the next
27-46 hr. On the day following operation, manometric measurements were made during addition and withdrawal of successive increments of normal saline solution.

\section{Results}

Postmortem procedures revealed enormously distended lungs weighing approximately 10 times more than those of normal lambs. The distended lungs displaced the diaphragm to the point where the diaphragm was concave downward bulging into the abdominal cavity.

Sham-operated animals, subjected to the entire procedure, including the exposure of the fetal trachea but without ligation were born alive. These animals were killed, and postmortem examinations were performed on the same day.

In the case of twins only one of which had been subjected to tracheal ligation (experiments 10 and 11), lung distention occurred only in that fetus with the tracheal ligation. In five cases (experiments 12-16), the tracheal ligation leaked on testing; in these animals, final lung weights varied widely, ranging from those characteristic of unoperated controls to those of fetuses with an intact tracheal ligature (Table I).

In the three near term fetuses in which a tracheal catheter had been inserted, periodic aspiration of fluid made at 27-46 hr following the opcration revealed rates of lung fluid formation of 0.015, 0.030, and $0.055 \mathrm{ml} / \mathrm{kg} / \mathrm{min}$ (Table II). The day after surgery, pressure measurements of lung fluid made via the catheter in two of these animals (animals $Y$ and $Z$, Table III) revealed an initial pressure of 12 and $19 \mathrm{~cm}$ saline (about one-half that necessary to cause fluid to flow spontaneously from the catheter). This pressure rose moderately (Table III) after injecting $150 \mathrm{ml}$ $0.85 \% \mathrm{NaCl}$ in $20-\mathrm{ml}$ increments into the fetal lung. The injected fluid was then removed; more fluid was removed from animals $Y$ and $Z, 9$ and $18 \mathrm{ml}$, respectively, than was injected, suggesting that the fetal lung continued to form fluid during the 50 and $67 \mathrm{~min}$ required for the manometric measurements.

Gestation times for singletons were within the normal range of 138 and 157 days except in three cases. These three pregnancies lasted 158, 158, and 161 days; the latter two pregnancies occurred in the same ewe, which had previously had a gestation period of normal duration (146 days) when carrying an unoperated fetus.

Gestation periods for twin births ranged from 138 to 146 days, or within the normal range for singletons. 
Table I. Total body weight, lung weight, and gestation time in controls and in newborn lambs after fetal tracheal ligation

\begin{tabular}{|c|c|c|c|c|c|}
\hline \multirow{2}{*}{$\begin{array}{c}\text { Experi } \\
\text { ment } \\
\text { no. }\end{array}$} & \multirow{2}{*}{ Ewe } & \multirow{2}{*}{$\begin{array}{l}\text { Birth } \\
\text { wt, } g\end{array}$} & \multicolumn{2}{|c|}{$\begin{array}{l}\text { Weight of both } \\
\text { lungs at birth }\end{array}$} & \multirow{2}{*}{$\begin{array}{c}\text { Gestation } \\
\text { time, } \\
\text { days }\end{array}$} \\
\hline & & & g & $\%$ body wt & \\
\hline & \multicolumn{5}{|l|}{ Singletons } \\
\hline 1 & $\Lambda$ & 5400 & 698 & 11.1 & 147 \\
\hline 2 & B & 7100 & 658 & 9.3 & $158^{1}$ \\
\hline 3 & C & 4900 & 864 & 17.6 & 158 \\
\hline 4 & $\mathrm{C}$ & 4220 & 579 & 13.7 & 161 \\
\hline 5 & $\mathrm{D}$ & 3850 & 497 & 12.9 & 145 \\
\hline 6 & $\mathbf{E}$ & 4870 & 838 & 17.2 & 149 \\
\hline 7 & $\mathrm{~F}$ & 5790 & 797 & 13.8 & 152 \\
\hline 8 & G & 5560 & 593 & 10.7 & 149 \\
\hline \multicolumn{6}{|c|}{ Twins, with both fetal tracheas ligated } \\
\hline & Twin $A$ & 4140 & 460 & 11.1 & 146 \\
\hline & Twin $B$ & 3850 & 419 & 10.9 & \\
\hline
\end{tabular}

Controls :

Twins, with 1 fetal trachea ligated (twin A) and 1 unop. crated (twin $B$ )

$\begin{array}{rrrrrr}10 \quad \text { I } & & & \\ & & 3900 & 426 & 10.9 & 141 \\ & \text { Truin } A & 2550 & 41 & 1.6 & \\ & \text { Twin } B & & & & \\ & \text { Awin } A & 3550 & 207 & 5.8 & 141 \\ & \text { Twin } B & 2800 & 46 & 1.6 & \end{array}$

Fetuses in which the tracheal ligature leaked

Singletons

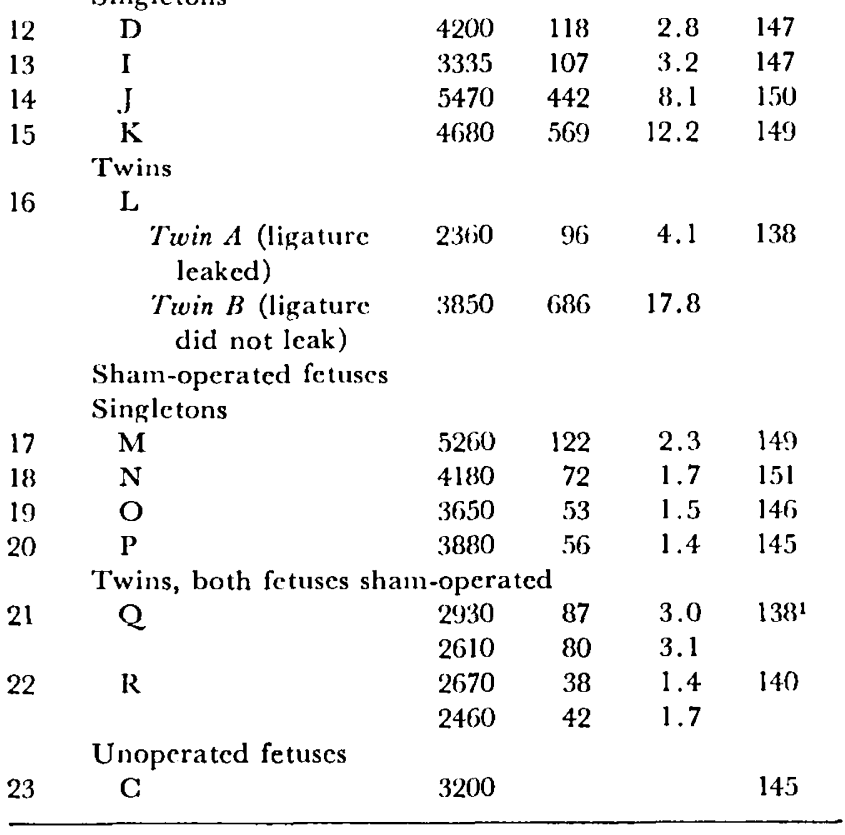

1 Ewe died before lambing.

Terrill and Hazel [19] report an average shortening of gestation time of 0.6 day for twins.

In most cases, the accuracy of the breeding date was checked at the time of operation by estimates of fetal age macle from measurements of the biparietal diameter of the fetal head. In singleton pregnancies values from Cloete's graphs [7] agreed with our breeding dates within a range of -5 to +2 days (seven pregnancies) and in twins within -5 to +6 days with one exception ( -11 days) (13 pregnancies).

\section{Discussion}

Our observations support the concept that the fetal lung secretes fluid. Distention of the lung after ligation

Table II. Rate of lung fluid recovery from fetal lambs ${ }^{1}$

\begin{tabular}{ccccc}
\hline Fetus & $\begin{array}{c}\text { Collection } \\
\text { period, hr:min }\end{array}$ & $\begin{array}{c}\text { Fluid } \\
\text { vol, } \mathrm{ml}\end{array}$ & $\begin{array}{c}\text { Fetal } \\
\mathrm{wt}, \mathrm{kg}\end{array}$ & $\begin{array}{c}\text { Rate of fluid } \\
\text { formation, } \\
\mathrm{ml} / \mathrm{kg} / \mathrm{min}\end{array}$ \\
\hline $\mathrm{X}$ & $46: 10$ & 135 & 3.7 & 0.013 \\
$\mathrm{Y}$ & $26: 56$ & 485 & 5.6 & 0.055 \\
$\mathrm{Z}$ & $44: 23$ & 270 & 3.3 & 0.030 \\
\hline
\end{tabular}

1 A catheter was inserted in the trachea of near term fetal lambs left in utero. After operation and with the ewe standing, all obtainable fluid was aspirated from the fetal trachea periodically at the rates shown.

Table III. Lung fluid pressures on distending the fetal lung with $0.85 \% \mathrm{NaCl}^{1}$

\begin{tabular}{|c|c|c|}
\hline \multirow{3}{*}{$\begin{array}{l}\text { Fluid added } \\
\text { (cumulative total) }\end{array}$} & \multicolumn{2}{|c|}{ Pressure } \\
\hline & Felus $Y$ & Felus $Z$ \\
\hline & \multicolumn{2}{|c|}{$\mathrm{cm}$ water } \\
\hline 0 & 12 & 19 \\
\hline 20 & 12 & 19 \\
\hline 40) & 17 & 21 \\
\hline 60 & $14-21-14$ & $27-21$ \\
\hline 80 & $16-20-14$ & $27-47-27$ \\
\hline 100 & $16-21-16$ & $33-25$ \\
\hline 120 & $18-23-16$ & $29-45-27$ \\
\hline 140 & $19-22-19$ & 28 \\
\hline 1.50 & $19-26-19$ & 32 \\
\hline 140 & 19 & \\
\hline 120 & 17 & \\
\hline 100 & 16 & \\
\hline 80 & 14 & $22-31-24$ \\
\hline 60 & 13 & \\
\hline 40 & 14 & 20 \\
\hline 20 & 12 & 19 \\
\hline 0 & 10 & \\
\hline-9 & 10 & \\
\hline-18 & & 16 \\
\hline
\end{tabular}

1 Pressures were measured with the ewe standing and from the estimated level of the fetal trachea. Variations indicated at various points presumably reflect either changes in the abdominal pressure of the ewe, transmitted to the fetus, or uterine contractions. Time required for study: fetus $Y, 50$ min; fetus $Z$, $67 \mathrm{~min}$. 
of the fetal trachea has been found in rabbits $[5,14]$, and in sheep [3]. The rate of lung fluid formation which we observed in near term sheep fetuses (0.013-0.055 $\mathrm{ml} / \mathrm{kg} / \mathrm{min})$ compares with rates of $0.014-0.13 \mathrm{ml} / \mathrm{kg} / \mathrm{min}$ observed in fetal lambs by others $[9,18]$. In experiments of such duration that the fetal lung becomes filled and distended with fluid, obviously some sort of equilibrium across the lung-lining cells must have been reached, either by cessation of formation of fluid in the lung or by a dynamic equilib. rium in fluid movement across the lining membrane. But with volumes of fluid insufficient to distend the fetal lung fully, our observations demonstrated that the pressures in the partially distended lungs remained low; additions of small volumes of fluid to the lung such as those apparently made by Reynolds [17] can be accommodated by distention of the lung without major changes in pressures; it was not necessary to postulate, as did Reynolds, a reversal of fluid flow across the lung-lining membrane into the fetal circulation.

A striking difference in the response to airway occlusion was apparent between the fetal and postnatal lung. Experimental or pathologic airway occlusion during fetal life leads to distention of the occluded portions of lung during fetal life, but, postnatally, atelectasis occurs. No ready explanation for this difference is apparent; loss of fluid by evaporation during ventilation cannot be responsible, since no evaporation occurs distal to an occlusion.

Sharp falls in pulmonary vascular perfusion pressures occur with expansion of the lung at birth [8]. It is likely, although unproved, that these changes are responsible for the altered effects of airway occlusion. It is interesting that neonatal infants with fluidl-filled lung tissue associated with airway occlusions that must have existed in utero have been reported [12]. Whether such fluid would be resorbed eventually uncler condlitions prevailing in postnatal life is not known.

We were curious to learn whether fetal tracheal ligation would influence gestation time The fetus is known to exert some control over the timing of its own birth [15]. Surfactant appears in fetal lungs shortly before term in several species $[4,6,11]$ and is carried up the trachea in the lung fluid [2] which is then in part swallowed and in part passed into the amniotic fluid with secretions of fetal lung [1]. The surface-active material is contained in the phospholipid fraction, more specifically in the lecithin fraction [10]. Surfactant is essential to postnatal survival. Syn- thesis of surfactant begins close to term in the various species studied. This fact and the known relation of phospholipids to the onset of labor led us to wonder whether these lung phospholipids could serve as the biochemical messenger though which the fetus, having become capable of extrauterine survival, signals the maternal uterus to initiate labor. From experiments in rabbits [16] and sheep [13] it is known that soya bean oil, which is rich in lecithins, sensitizes the uterus of the doe or ewe to oxytocin, precipitating premature clelivery, in rabbits, as early as day 21 of gestation (normal term, 30-32 days). Normally the uterus of the pregnant doe is unresponsive to oxytocin until day 29 or 30 . To test whether lung phospholipids reaching the maternal uterus via the amniotic fluid might trigger the onset of labor, we interrupted the flow of fetal lung fluid by tracheal ligation with the thought that prolonged gestation might follow. This experimental procedure, however, failed to influence gestation time consistently. All but three singleton births fell in the normal range; these gestations extended 158, 158, and 161 days. We are unable to explain the three prolongations, but the data as a whole fail to support a relation of tracheal ligation of the fetus to prolonged gestation. Our data did not indicate whether phospholipids from other fetal or maternal sources may influence the initiation of labor, but only that lung secretions reaching the amniotic fluid via tracheal flow did not play a role.

\section{Summary}

We performed ligation of the trachea in 16 fetal lambs at 74-129 days of gestation. Normal term ranges from 138 to 157 days. Fetal lambs with ligated tracheas were carried normally to term and delivered spontaneously, at which time they diecl. At autopsy, the lungs were found to be greatly distended with fluid, and were 10 times heavier than normal weight. Sham-operated lambs showed no such changes. Measurement of rate of tracheal fluid flow in three near term fetuses revealed flow rates of $0.013-0.030 \mathrm{ml} / \mathrm{kg} / \mathrm{min}$; infusion of saline into the lungs of two of these animals showed that infusion in successive $20-\mathrm{ml}$ increments of $150 \mathrm{ml}$ $0.85 \% \mathrm{NaCl}$ caused only a modest rise in pressure. The ready recovery of the infused fluid indicated that it had distended the lung and had not passed across the pulmonary alveolar lining membrane into the fetal circulation.

Gestation times were not altered by tracheal ligation of the fetus. The fetal lung fluicls contain surface-active phospholipids. Certain (unknown) phospholipids con- 
tained in an extract of soya bean oil are capable of sensitizing the rabbit myometrium to permit premature delivery. The fetus is known to participate in the timing of its own birth, and we conjectured whether fetal tracheal ligation could lead to prolonged pregnancy by blocking exposure of the maternal uterus to phospholipids contained in secretions of the fetal lung. Gestation time was not altered, however, and other mechanisms for fetal control of pregnancy duration must be sought.

\section{References and N'otes}

1. Answs, F. H., Desit.eis, 1). 'T., AND Towers, B.: Control of flow of fetal lung fluid at the laryngeal outlet. Resp. 1'hysiol., 2: 302 (1967).

2. Adans, F. H., and Fujlwaka, T.: Surfactant in fetal lamb traclical fluid. J. Pediat., 63: 537 (1963).

3. Berton, J. P.: Effects de la ligature de la trachéce clee le foetus de mouton à la fin du $l^{m}$ et an $2^{\circ}$ tiers de la gestation: accumulation de liquide dans les ramifications bronchique primitives et anasarque foeto-placentaire. In: Bulletin of the Association of Anatomists, 5tth Congress, no. 145 (Sofia, 1969).

4. Beckingilam, S., MCNakt, W. F., and Sommers, S. C.: I'ulmonary alveolar cell inclusions: their development in the rat. Scicuce, 145: 1192 (1961).

5. Carmile, J. A., Frjemman, F., and Adnas, F. H.: Fetal tracheal ligation and Iung development. Aner. J. Dis. Child., 109: $452(1965)$

6. Cimba, N., Adnas, F. II., Nozaki, M., and Norman, A.: Changes in lamb-lung lipids during gestation. Proc. Soc. lixp. Biol. Med., 122: 60 (1966).

7. Clokte, J. H. L.: Prenatal growth in the merino sheep. Onderstepoort J. Vet. Sci. Anim. Indt., 13: 117 (1939).

8. D.Awes, G. S.: Foetal and Nconatal Physiology, p. 79. (Y'car Book P'ublishers, Chicago, 1969).

9. FNuörnisg, G., AND ADdsts, F. H.: Surface properties of fetal lamb) tracheal fluid. Amer. J. Obstet. Gynce., 92: 563 (1965).
10. FujwakA, T., HiroNo, II., AND ArakawA, T.: Chemical identification of the surface-active material isolated from calf lung. 'Tohoku J. Exp. Med., s5: 33 (1965).

11. Gleck, I., Motoyama, E. K., Smits, H. L., ANi) Kutovicit, M. V.: The biochemical development of surface aclivity in the mammalian lung. Pediat. Res., 1: 237 (1967).

12. Griscom, N. T., Citfiton Itarkis, G. B., Womt, M. E. B., VAWTER, G. I., AND Ekaki.s, A. J.: Fluid-filled lung due to arway obstruction in the newborm. Pediatrics, 13: 383 (1969).

13. J.tst., F.: Infusion of phosphatides in animals in the last third of gestation: uterine contractility. Symp. Bibl. Gynacc., 12: $191(1966)$.

14. Jost, A., AND Pol.tcakt, A.: Contribution experimentale à l’étude du développement prénatal du poumon chez le lapin. Arch. Anat. Microsc. Morphol. Exp., 37: 323 (1948).

15. Lavman, J. 'T.: Delays during reproduction and their effects on the embryo and fetus. 3. Delayed parturition. New Fingl. J. Med., 278: 1092 (1968).

16. Letkkainis, T. U., ANo CsAPO, A. I.: Induction of premature labor in the rabbit after pretreatment with phospholipids. Fertil. Steril., 1t: 65 (1963).

17. Revsotos, S. R. MI.: Reversible movement of fluid across the foetal lung. Nature, 202: 197 (1964).

18. Ross, B. B.: Comparison of foctal pulmonary fluid with foctal plasma and ammiotic fluid. Nature, 199: 1100 (1963).

19. 'Tekrill, C. F., AND Hazri., L. N.: Length of gestation in range shecp. Amer. J. V'et. Res., $8: 66$ (1947).

20. W'e are indebted to the Schering Corporation for their donation of progesterone (Proluton) and to DR. W. A. CowAN of the University of Connecticut for making available cwes with dated pregnancies for a part of our work.

21. Supported by Public Ilealth Service Research Grant no. 5 ROI HD-01003 and by the Association for Aid to Crippled Children, New York City.

22. Reguests for reprints should be addressed to: Jonatuns ' $Г$. LANMAN, M.D., Department of Pediatrics, State University of New York, Downstate Medical Center, 450 Clarkson Avenue, Brooklyn, N. Y. 11203 (USA).

23. Accepted for publication December 8,1970 . 